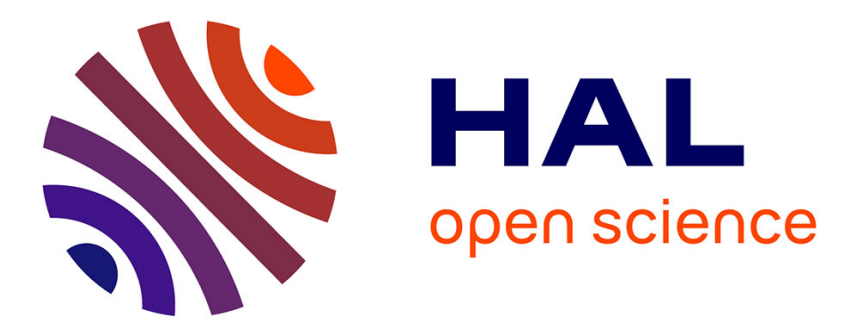

\title{
Flow boiling of water in a minichannel: The effects of surface wettability on two-phase pressure drop
}

Hai Trieu Phan, Nadia Caney, Philippe Marty, Stéphane Colasson, Jérôme

Gavillet

\section{- To cite this version:}

Hai Trieu Phan, Nadia Caney, Philippe Marty, Stéphane Colasson, Jérôme Gavillet. Flow boiling of water in a minichannel: The effects of surface wettability on two-phase pressure drop. Applied Thermal Engineering, 2011, 10.1016/j.applthermaleng.2011.02.036 . hal-00743916

\section{HAL Id: hal-00743916 https://hal.science/hal-00743916}

Submitted on 22 Oct 2012

HAL is a multi-disciplinary open access archive for the deposit and dissemination of scientific research documents, whether they are published or not. The documents may come from teaching and research institutions in France or abroad, or from public or private research centers.
L'archive ouverte pluridisciplinaire HAL, est destinée au dépôt et à la diffusion de documents scientifiques de niveau recherche, publiés ou non, émanant des établissements d'enseignement et de recherche français ou étrangers, des laboratoires publics ou privés. 


\section{Accepted Manuscript}

Title: Flow boiling of water in a minichannel: The effects of surface wettability on twophase pressure drop

Authors: Hai Trieu Phan, Nadia Caney, Philippe Marty, Stéphane Colasson, Jérôme Gavillet

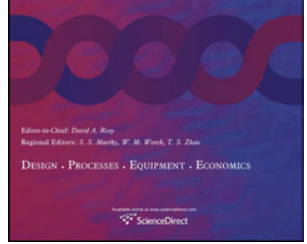

PII:

$$
\text { S1359-4311(11)00117-7 }
$$

DOI:

10.1016/j.applthermaleng.2011.02.036

Reference: $\quad$ ATE 3447

To appear in: Applied Thermal Engineering

Received Date: 14 December 2010

Revised Date: 18 February 2011

Accepted Date: 20 February 2011

Please cite this article as: H.T. Phan, N. Caney, P. Marty, S. Colasson, Jérôme Gavillet. Flow boiling of water in a minichannel: The effects of surface wettability on two-phase pressure drop, Applied Thermal Engineering (2011), doi: 10.1016/j.applthermaleng.2011.02.036

This is a PDF file of an unedited manuscript that has been accepted for publication. As a service to our customers we are providing this early version of the manuscript. The manuscript will undergo copyediting, typesetting, and review of the resulting proof before it is published in its final form. Please note that during the production process errors may be discovered which could affect the content, and all legal disclaimers that apply to the journal pertain. 


\title{
Flow boiling of water in a minichannel: The effects of surface wettability on two-phase pressure drop
}

\author{
Hai Trieu PHAN ${ }^{\mathrm{a}, \mathrm{b}}$, Nadia CANEY $^{\mathrm{a},{ }^{*}}$, Philippe MARTY ${ }^{\mathrm{a}}$, Stéphane COLASSON $^{\mathrm{b}}$, Jérôme GAVILLET ${ }^{\mathrm{c}}$
}

${ }^{a}$ Université Joseph Fourier, LEGI, BP 53, 38041 Grenoble Cedex 9, FRANCE

${ }^{b}$ LITEN/GRETh, CEA Grenoble, 17 rue des martyrs, 38054 Grenoble Cedex 9, FRANCE

${ }^{c}$ LITEN/LTS, CEA Grenoble, 17 rue des martyrs, 38054 Grenoble Cedex 9, France

\begin{abstract}
Experiments were performed to study the effects of surface wettability on two-phase pressure drop of flow boiling of water at atmospheric pressure. The test channel is a single rectangular channel $0.5 \mathrm{~mm}$ high, $5 \mathrm{~mm}$ wide and $180 \mathrm{~mm}$ long. The mass flux was set at $100 \mathrm{~kg} / \mathrm{m}^{2} \mathrm{~s}$ and $120 \mathrm{~kg} / \mathrm{m}^{2} \mathrm{~s}$, respectively. The base heat flux varied from 30 to $80 \mathrm{~kW} / \mathrm{m}^{2}$. Water enters the test channel under subcooled conditions. The study has been performed at low exit vapour quality (less than 0.1). The samples are either hydrophilic like Polydimethylsiloxane (SiOx), Titanium (Ti), Diamond-Like Carbon (DLC) or hydrophobic like Polydimethylsiloxane (SiOC). These surfaces have static contact angles of $26^{\circ}, 49^{\circ}, 63^{\circ}$ and $103^{\circ}$, respectively. It was observed that the total two-phase pressure drop significantly increases with the static contact angle. In particular, the average deviation between the highly-wetted and the unwetted surfaces is about $170 \%$. To explain this observation, the "wetting pressure drop" notion caused by the surface tension forces generated at the triple contact lines is introduced. Afterwards, a model is proposed to predict the wetting pressure drop as a function of the static contact angle. This model shows a good agreement with the experimental data with $86 \%$ of the data included within the lines of $20 \%$ error.
\end{abstract}

25 Key words: contact angle, flow boiling, pressure drop, microchannel, nanocoating, surface wettability

\section{Introduction}

Power systems, such as electronic components or fuel cells, are dissipating more and more heat due to progressively increasing power densities associated with continuous advances in their miniaturization. In order to prevent damages to their components, this generated heat must be efficiently removed. Various cooling modes can be applied, such as air convection or liquid and boiling flows.

Air convection is the most widely-used method because of its easy implementation. However, this mode exhibits a poor heat transfer performance and its operational limits have been already reached. As a consequence, cooling systems by liquid and boiling flows have been increasingly developed. Flow boiling is the most efficient mode as it provides better heat transfer efficiencies. Indeed, for this cooling mode, a part of heat is transferred into the latent heat during liquid-vapour phase change in addition to convective effects.

In the present study, flow boiling was generated inside the systems called mini-and microchannels, which are channels of small size with hydraulic diameters of less than $3 \mathrm{~mm}$. Over the last decade, mini- and microchannels have attracted the attention of researchers in

\footnotetext{
${ }^{*}$ Corresponding author. Tel.:+33438789422; fax : +33438785435

Email address: nadia.caney@cea.fr (Nadia CANEY)
} 
the field of heat and mass transfer, because they enable the development of compact cooling systems which can be adapted to miniaturized power components.

In order to distinguish between macro and microscale flow boiling, the threshold to confined bubble flow is one of the most widely used criterions. Following the classification by Kew and Cornwell [1], channels are classified as microchannels if Co $\geq 0.5$, where Co is the confinement number defined as:

$$
\operatorname{Co}=\left[\frac{\sigma_{l v}}{g\left(\rho_{l}-\rho_{v}\right) D_{h}^{2}}\right]^{1 / 2}
$$

wherein $D_{h}$ is the hydrodynamic diameter.

Kandlikar and Grande [2] suggested another classification based on the hydrodynamic diameter: conventional channels $\left(D_{h}>3 \mathrm{~mm}\right)$, minichannels $\left(200 \mu \mathrm{m}<D_{h}<3 \mathrm{~mm}\right)$ and microchannels $\left(D_{h}<200 \mu \mathrm{m}\right)$.

In macro-size channels, the capillary effects are negligible compared to the inertia and viscous effects. However, in microchannels, the capillary effects become important and would play a significant role in the thermohydraulics. As an example, the effects of the surface wettability on two-phase pressure drop were discussed by several works in the literature [3]-[8].

Rapolu and Son [3] investigated the effects of the static contact angle on the two-phase pressure drop. They performed experiments of adiabatic co-current flow of air-water mixtures in horizontal microchannels of both square and circular geometries of $700 \mu \mathrm{m}$ hydraulic diameter, for various liquid volumetric flow ratios. They observed that the two-phase pressure drop significantly depends on the surface wettability; especially, it increases with the static contact angle.

Lee and Lee [4] investigated the two-phase pressure drop of plug flows of air-water mixtures, in round channels for three different tube materials, i.e. glass, polyurethane and Teflon, respectively, with the inner diameter ranging from $1.62 \mathrm{~mm}$ to $2.16 \mathrm{~mm}$. They observed different behaviours between the wet-plus flow (with the glass tube) and the dry-plug flow (with the polyurethane and Teflon tubes). Thus, they highlighted the pressure drop by displacement of the contact lines as an important parameter to be considered for prediction of the two-phase pressure drop in the dry-plug flow regime [5]. They also suggested a model to predict this pressure drop based on dynamic contact angle analysis.

80 Yu et al. [6] conducted experiments in adiabatic conditions with round channels of various diameters $(0.546,0.763,1.018,1.555,2.075 \mathrm{~mm})$. To modify the wettability, they used mixtures of air and various fluids such as water or ethanol. Using experimental data, they calculated the pressure drop due to displacement of the contact lines and observed that this pressure drop increases with the static contact angle.

Recently, Liu et al. [7] investigated the flow boiling modes in three microchannels with identical sizes at $105 \times 1000 \times 30000 \mu \mathrm{m}$ but at different wettability. The authors tested two different contact angles, $36^{\circ}$ and $103^{\circ}$. They observed cyclic flow process which leads to cyclic temperature and pressure fluctuation when the channel is hydrophilic. 
Choi et al. [8] studied surface wettability effect on flow boiling in rectangular microchannels with contact angles at $25^{\circ}$ and $105^{\circ}$. The authors observed that the pressure drop in the hydrophobic rectangular microchannel was higher than that in the hydrophilic rectangular microchannel, which was highly related with unstable motions of bubble and liquid film. They concluded that the wettability is the important parameter on two-phase heat and mass transfer.

In the present study, the effects of surface wettability on two-phase pressure drop in boiling conditions are presented. The test channel is rectangular with hydraulic diameter of $0.96 \mathrm{~mm}$ and length of $180 \mathrm{~mm}$. The confinement number is equal to 2.6 , and hence the test channel is considered as a microchannel according to Kew and Cornwell theory [1], but as a minichannel according to Kandlikar and Grande [2] classification.

\section{Sample surface fabrication}

\subsection{Techniques of surface coating}

Thin film technologies have been widely developed over the past decades, particularly for the microelectronics and $\mathrm{IT}^{2}$-related components and systems. Their direct implementation in the fields of heat and mass transfer is mostly recent and opens large expectations in making new surfaces which have not been assessed before in heat exchange systems. Table 1 summarizes the surface solutions realized in the present work using Physical Vapour Deposition (PVD) and Plasma Enhanced Chemical Vapour Deposition (PECVD). Those surfaces mainly address heating, structuring and wetting functions which were necessary to operate the experimental heat-exchanger systems.

Table 1. Summary of coating processes used in this study.

\begin{tabular}{lllll}
\hline Material & Notation & Technique & Thickness & Function \\
\hline Titanium & Ti & PVD & $3-4 \mu \mathrm{m}$ & Heating \& structuring layer \\
Diamond-like carbon & DLC & PECVD & $0.5-1 \mu \mathrm{m}$ & Electrical-insulating \& structuring layer \\
Low-carbon PDMS & SiOx & PECVD & $<50 \mathrm{~nm}$ & Wetting layer \\
High-carbon PDMS & $\mathrm{SiOC}$ & PECVD & $<50 \mathrm{~nm}$ & Wetting layer \\
\hline
\end{tabular}

\subsection{Fabrication processes}

Smooth sample surfaces were fabricated for determination of the surface wettability effects. It is necessary that all the sample surfaces have the same geometry with only change in contact angle. In other words, they should have the same dimensions (length, width and thickness) and the same topography at microscale. The sample surfaces are thereby produced by deposition of nanoparticles through patterning masks using techniques of physical and chemical vapour depositions according to the following steps (cf. Figure 1):

- Step 1: deposition of titanium (Ti) layer.

The base substrate is a Pyrex wafer of $200 \mathrm{~mm}$ diameter and $1.1 \mathrm{~mm}$ thickness. This layer is used as a heating element. It consists of a rectangular track corresponding to the testing area and pads for electrical connections.

\footnotetext{
${ }^{2}$ Information Technologies

${ }^{3}$ Polydimethylsiloxane
} 
This layer is used for electrical insulation.

- Step 3: deposition of nanocoating layer.

This layer enables modification of the surface wettability in a larger threshold. The deposition layers are hydrophilic PDMS (SiOx) and hydrophobic PDMS (SiOC), respectively.

Pyrex wafer (200), thickness: $1.1 \mathrm{~mm}$

$\approx \approx$ Titanium layer, thickness: 3-4 $\mu \mathrm{m}$

2. DLC electrical insulation layer, thickness: 0.5-1.5 $\mu \mathrm{m}$

双 Nanocoating layer, thickness: $\leq 50 \mathrm{~nm}$

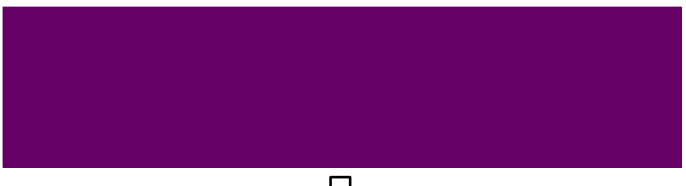

$\prod$ Step 1

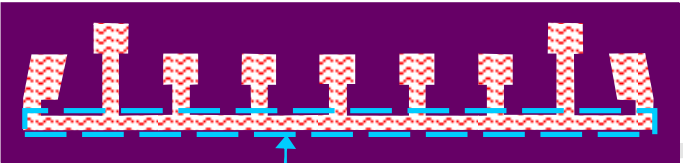

Test area
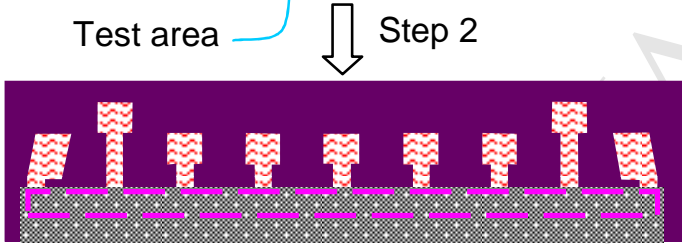

$\lceil\operatorname{Step} 3$

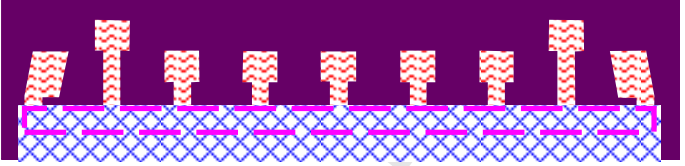

a)
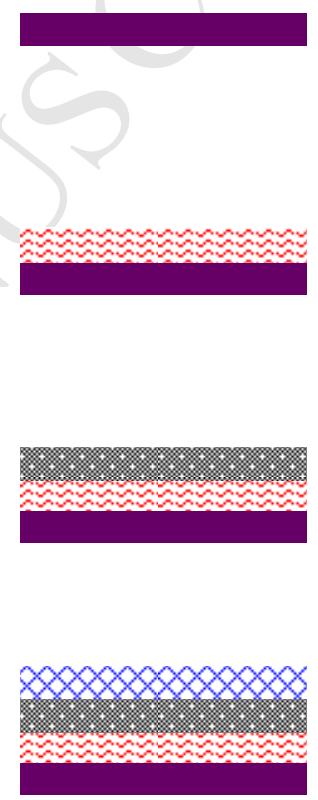

b)

Figure 1. Sample fabrication processes: a) top view and b) side view.

140 Applying the above method, four smooth sample surfaces were fabricated and characterized such as:

- Titanium (Ti) surface made by step 1 ,

- Diamond-Like Carbon (DLC) surface made by step 1 and 2,

- Hydrophilic PDMS (SiOx) surface and hydrophobic PDMS (SiOC) surface made by step 1,2 and 3.

\subsection{Electrical connexions}

The testing area is $5 \mathrm{~mm}$ wide and $180 \mathrm{~mm}$ long. It is divided into eight sections called " $\mathrm{S}_{1}$ ", " $\mathrm{S}_{2}$ "... and "S $\mathrm{S}_{8}$ ", respectively, as shown in Figure 2. Dimensions of these sections are shown in Table 2. The testing area is heated by Joule effect from the metallic layer. Electrical wires are fixed on the electrical pads by mechanical support. Current and voltages of different sections are measured by Agilent 34970A and a 0.01- $\Omega$ shunt, which has an accurately known resistance for determination of current by measurement of voltage. 


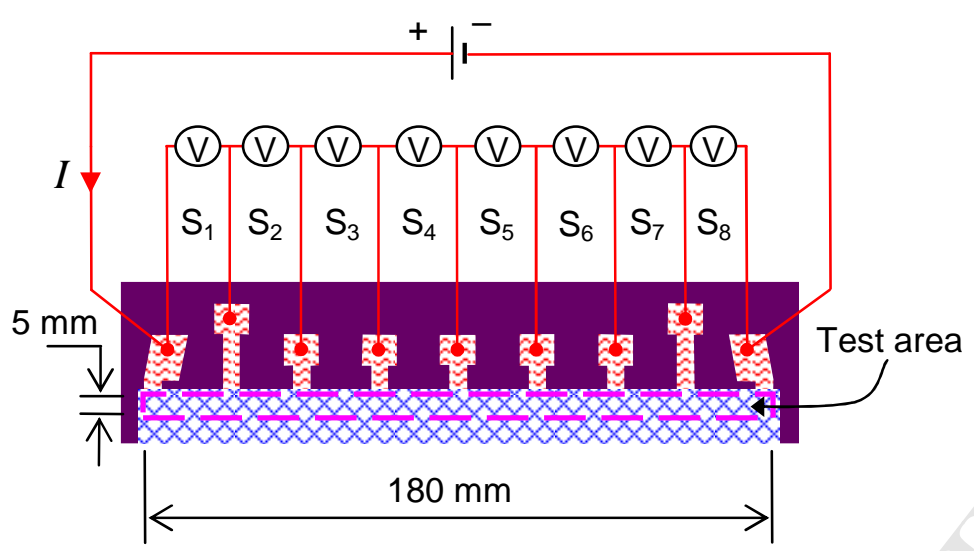

Figure 2. Schematic view of electrical connexions.

Table 2. Dimensions of the testing area sections.

\begin{tabular}{lllllllll}
\hline Name & $\mathrm{S}_{1}$ & $\mathrm{~S}_{2}$ & $\mathrm{~S}_{3}$ & $\mathrm{~S}_{4}$ & $\mathrm{~S}_{5}$ & $\mathrm{~S}_{6}$ & $\mathrm{~S}_{7}$ & $\mathrm{~S}_{8}$ \\
\hline Width $(\mathrm{mm})$ & 5 & 5 & 5 & 5 & 5 & 5 & 5 & 5 \\
Length (mm) & 25 & 20 & 22.5 & 22.5 & 22.5 & 22.5 & 20 & 25 \\
\hline
\end{tabular}

160 Figure 3 shows image of a typical wafer, on which two sample surfaces are produced. These surfaces are identical but only one of them is used for boiling test (surface $a$ ) and the other one is saved as a backup copy (surface $b$ ). Furthermore, close to the wafer edge, samples for surface characterisations are also deposited (surfaces $c$ and $d$ ). They are used to determine the surface topography by field-emission gun scanning electron microscopic (FEG-SEM) as well as to measure the surface wettability.

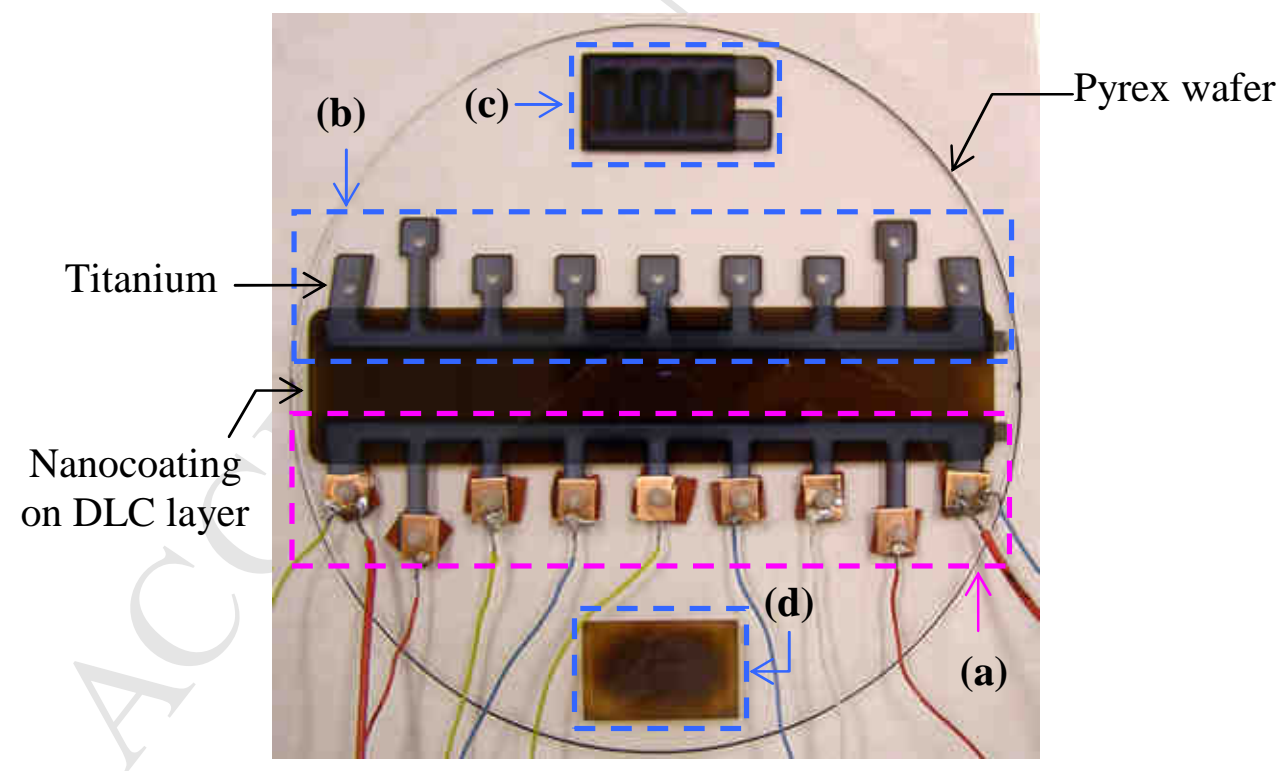

Figure 3. Image of a typical wafer: a) test surface with electrical connexions, b) backup surface and c) and d) samples for surface characterisations.

Once a sample surface is produced, stabilization of its deposition layers is made by annealing in a vacuum chamber at $300{ }^{\circ} \mathrm{C}$ for 3 hours. Afterwards, it is put inside a thermostat where the temperature is measured by a platinum probe of $0.1{ }^{\circ} \mathrm{C}$ accuracy. At steady state, 175 the temperature of the sample surface could be determined from the temperature of the thermostat. For temperature between $20{ }^{\circ} \mathrm{C}$ and $90{ }^{\circ} \mathrm{C}$, the electrical resistances of different sections of the sample surface are determined. In this way, the local wall temperature at each 


\section{ACCEPTED MANUSCRIPT}

section of the sample surface can be deduced from measurements of the electric resistance by 180 using the Resistance/Temperature $(\mathrm{R} / \mathrm{T})$ curve.

\subsection{FEG-SEM images}

In order to estimate the thicknesses of the deposition layers, images of the sample surfaces are taken using a field-emission gun scanning electron microscopic (FEG-SEM). For instance, FEG-SEM images of SiOC surface are shown in Figure 4. Pixel analyses give the thicknesses

185 of titanium (Ti) and diamond-like carbon (DLC) layers of about $3.5 \mu \mathrm{m}$ and $1 \mu \mathrm{m}$, respectively. The thickness of the nanocoating layer is about $50 \mathrm{~nm}$.
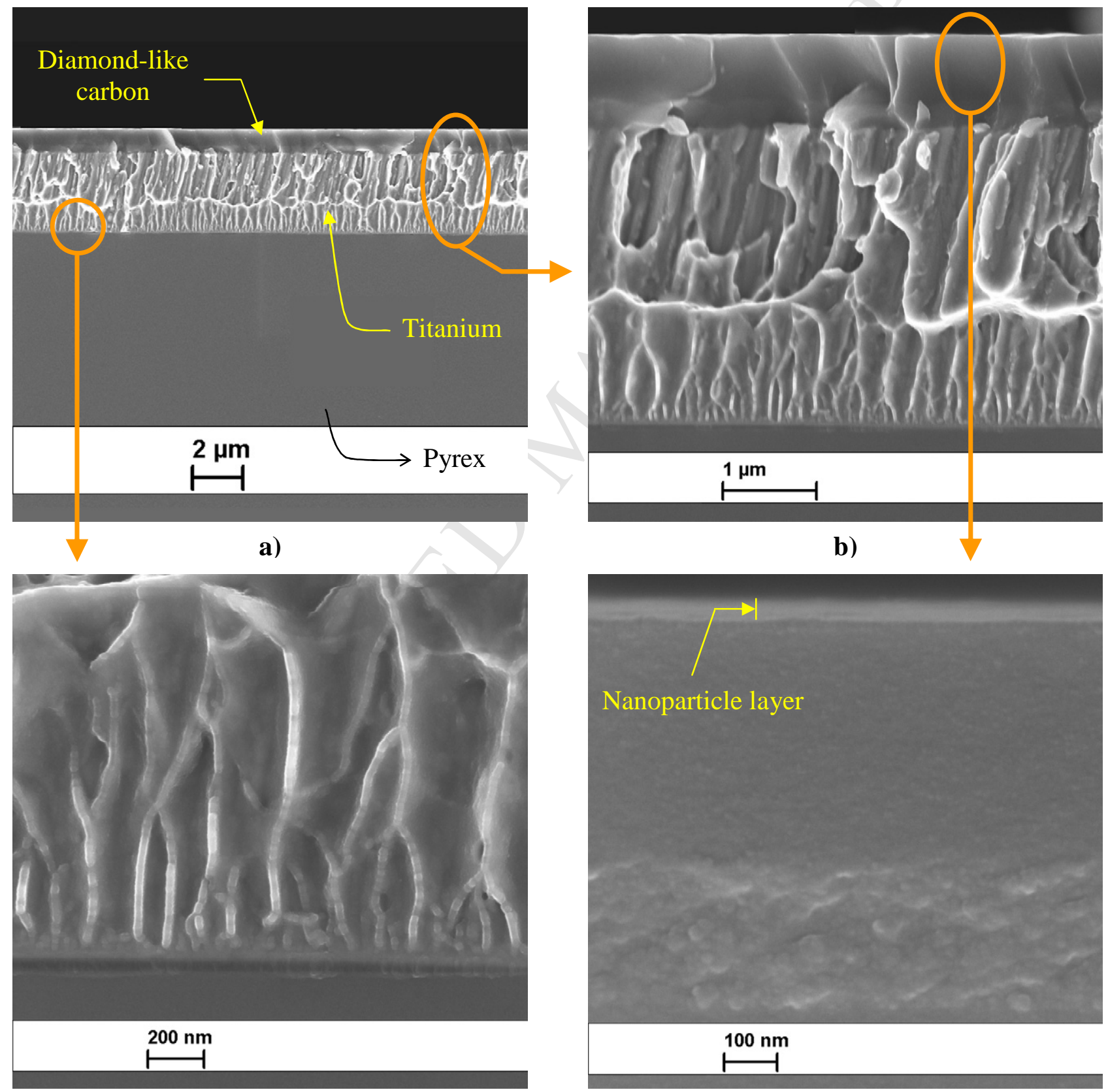

c)

d)

190 Figure 4. FEG-SEM images of SiOC surface in the side view: a) and b) deposition layers on Pyrex wafer, c) nanoparticle layer and d) interface between titanium layer and Pyrex wafer. 


\section{Experimental apparatus and procedure}

\subsection{Experimental apparatus}

195 The experimental setup is shown in Figure 5. It consists of a test section, a condenser with a cooling bath, a liquid pump (ISMATEC MCP_Z), a mass flowmeter (Micro Motion Elite MVD) and a pre-heater. A reservoir is used to store the fluid and to control the working pressure at atmospheric pressure.

200 The experimental facility is instrumented with an absolute pressure transducer ( 1 bar) to measure the pressure at the inlet of the test section, and a differential pressure transducer (100 mbar) to measure the pressure drop across the test section. The absolute pressures at the outlet of the condenser and at the inlet of the pre-heater are also measured. K-type thermocouples are inserted at different locations to measure the bulk fluid temperature.

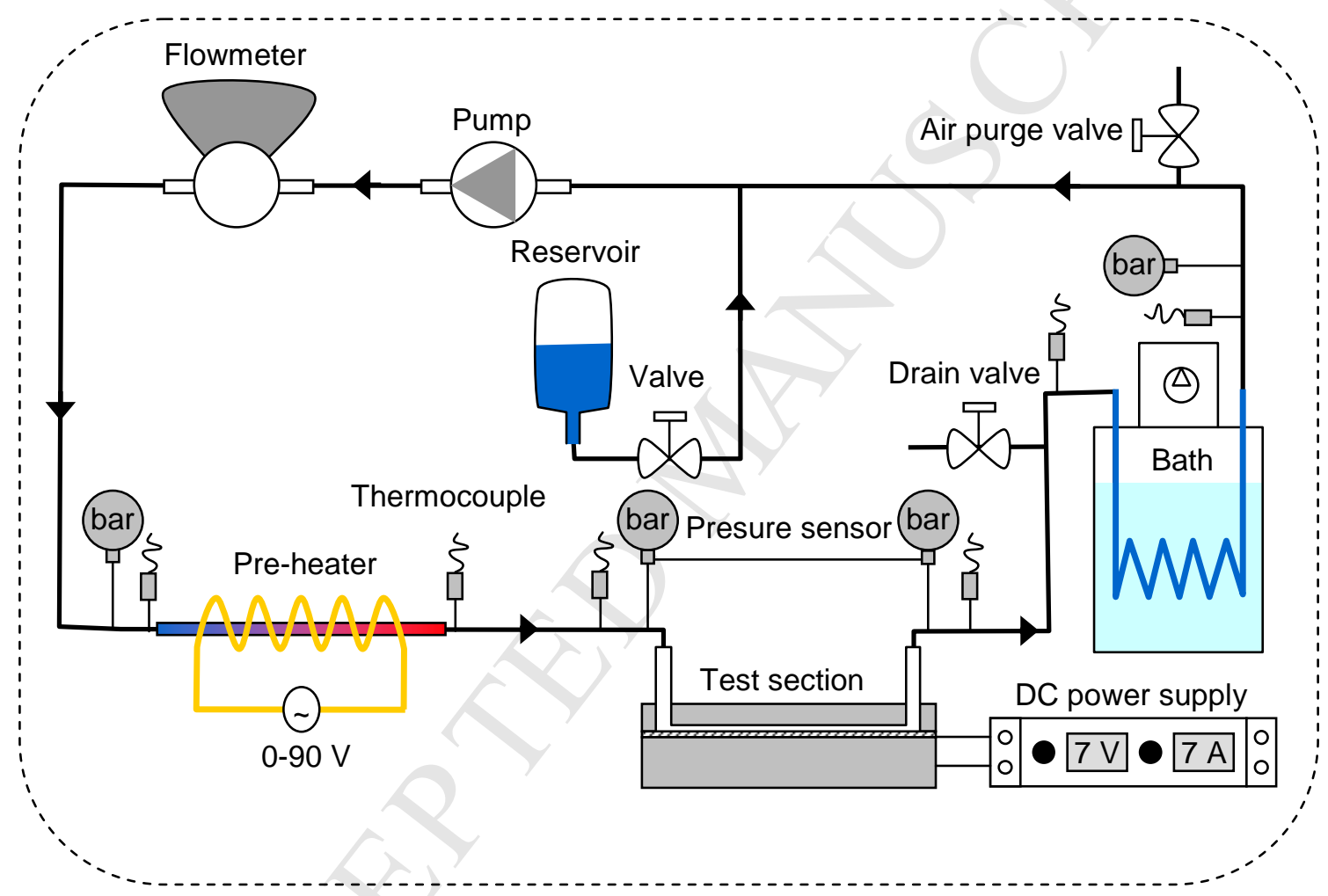

Figure 5. Schematic view of the experimental apparatus.

\subsection{Experimental procedure}

Before each test point, degassing of water is made by boiling at saturated temperature (100 ${ }^{\circ} \mathrm{C}$ ) for two hours. Then, the desired flow rate is established and the electrical power is raised in steps lasting a few minutes each until a new steady state is achieved. The flow rate, current, voltages, pressures, and bulk temperatures are monitored and recorded at each power step

215 with a data logger (Agilent 34970A) connected to a computer. The mass flux was set at 100 $\mathrm{kg} / \mathrm{m}^{2} \mathrm{~s}$ and $120 \mathrm{~kg} / \mathrm{m}^{2} \mathrm{~s}$, respectively and the base heat flux was varied from 30 to $80 \mathrm{~kW} / \mathrm{m}^{2}$. Flow visualisation was made by a high speed camera set at 500 or $1000 \mathrm{fps}$. 


\section{Single-phase flow validation tests}

\subsection{Heat loss}

Due to air convection and radiation around the test section, the working fluid loses a part of its energy $Q^{o}$ loss when flowing along the test channel even though no electrical power is generated:

$$
Q_{\text {loss }}^{o}=\dot{m} C_{p}\left[T_{f, \text { in }}-T_{f, \text { out }}^{o}\right]
$$

wherein $\dot{m}$ is the mass flow, $C_{p}$ is the liquid specific heat, $T_{f, i n}$ is the fluid inlet temperature and $T_{\text {fout }}^{o}$ is the fluid outlet temperature when the fluid is not heated by electrical power from the sample surface $\left(T_{f, \text { out }}^{o} \leq T_{f, \text { in }}\right)$.

230 Now, if an electrical power $Q_{e}$ is generated from the sample surface, a part of it $Q_{e, f}$ goes toward the working fluid and the other part $Q_{d, l o s s}$ is dissipated by conduction through the Pyrex wafer as shown in Figure 6:

$Q_{e}=Q_{e, f}+Q_{d, l o s s}$

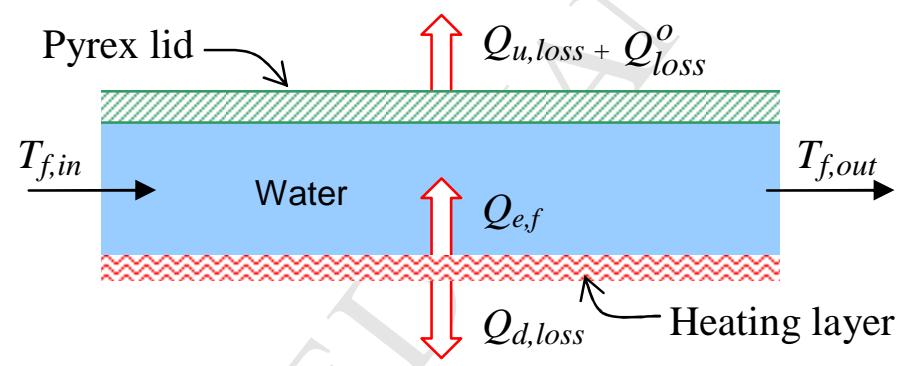

Figure 6. Schematic view of distribution of heat flux generated by Joule effect from the titanium layer.

For the heat flux received by the fluid $Q_{e, f}$, a part contributes to recoup the initial heat loss

$Q_{\text {loss, }}^{o}$ another part contributes to heat the fluid up and the other $Q_{u, l o s s}$ is dissipated to the ambient:

$Q_{e, f}=Q_{\text {loss }}^{o}+\dot{m} C_{p}\left(T_{f, \text { out }}-T_{f, \text { in }}\right)+Q_{u, \text { loss }}$

Eqs. (2), (3) and (4) give the following relation of energy balance in single-phase flow:

$Q_{e}=\dot{m} C_{p}\left[T_{f, \text { out }}-T_{f, \text { out }}^{o}\right]+\dot{m} C_{p}\left(T_{f, \text { out }}-T_{f, \text { in }}\right)+\left(Q_{d, \text { loss }}+Q_{u, \text { loss }}\right)$

The overall heat loss due to generation of electrical power is defined as:

$Q_{\text {loss }}=Q_{d, \text { loss }}+Q_{u, l o s s}$

Eqs. (5) and (6) imply: 


$$
Q_{\text {loss }}=Q_{e}-\dot{m} C_{p}\left[T_{f, \text { out }}-T_{f, \text { out }}^{o}\right]+\dot{m} C_{p}\left(T_{f, \text { out }}-T_{f, \text { in }}\right)
$$

Shown in Table 3 a summary of the heat flux components in the energy balance.

Table 3. Heat fluxes balance.

\begin{tabular}{ll}
\hline Symbol & Description \\
\hline$Q_{\text {loss }}^{o}$ & Heat loss before generation of electrical power due to air convection and radiation \\
$Q_{e}$ & Electrical power \\
$Q_{d, \text { loss }}$ & Electrical power loss by conduction through the Pyrex wafer \\
$Q_{e, f}$ & Electrical power towards the working fluid \\
$Q_{u, l o s s}$ & Part of $Q_{e, f}$ dissipated to the ambient \\
$Q_{\text {loss }}$ & Overall heat loss due to electrical power generation, $Q_{\text {loss }}=Q_{d, \text { loss }}+Q_{u, l o s s}$ \\
\hline
\end{tabular}

\subsection{Single-phase pressure drops}

Experiments were performed to determine this heat loss according to Eq. (7). The inlet temperature of water was fixed at $75^{\circ} \mathrm{C}$. The mass flux was set at $120 \mathrm{~kg} / \mathrm{m}^{2} \mathrm{~s}$ since the operating mass fluxes for boiling tests are 100 and $120 \mathrm{~kg} / \mathrm{m}^{2} \mathrm{~s}$, respectively. As shown in Figure 7, the heat loss from the sample surface to the fluid flow is less than $5 \%$ for base heat fluxes greater than $10 \mathrm{~kW} / \mathrm{m}^{2}$. The heat loss generated by electrical power can be thereby neglected, i.e. it is taken into account as the uncertainty in measurement of the heat flux.

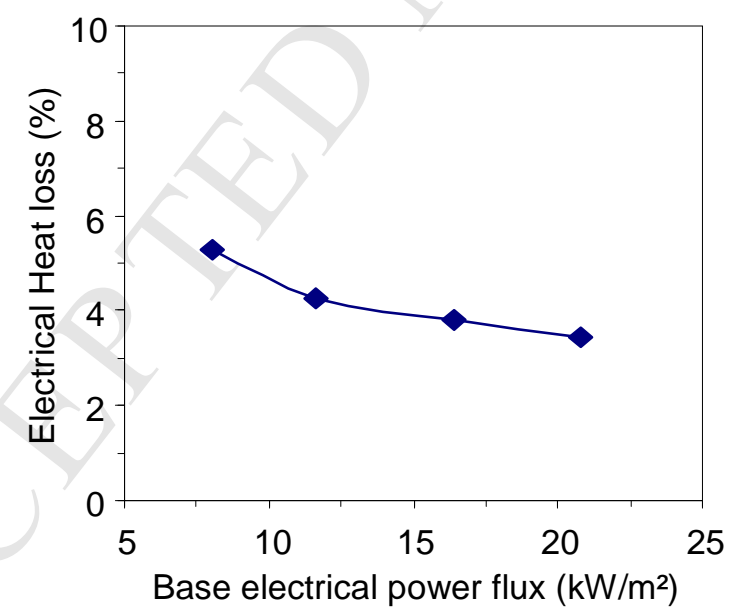

Figure 7. Electrical heat loss vs. electrical power generated by Joule effect at $120 \mathrm{~kg} / \mathrm{m}^{2} \mathrm{~s}$.

In the present study, the static pressure drop is negligible because the test channel is placed in the horizontal position (cf. Figure 8). Numerical calculations and experimental measure-ments show that the frictional pressure drop in the intermediate tubes between the pressure transducer and the test channel is less than $0.1 \mathrm{mbar}$, which is in the order of the measurement uncertainty. This pressure drop is thereby neglected. Indeed, in the intermediate tubes, the fluid velocity is relatively low $(\leq 0.06 \mathrm{~m} / \mathrm{s}$ on the operating conditions). Therefore, the measured pressure drop is approximated to the sum of the frictional and singular pressure drops in the test channel as: 
$\Delta P_{\exp }=\Delta P_{\text {frict }}+\Delta P_{\text {sing }}$

wherein $\Delta p_{\text {frict }}$ is the frictional pressure drop along the test channel and $\Delta p_{\text {sing }}$ is the singular pressure drop at the inlet and outlet of the test channel.

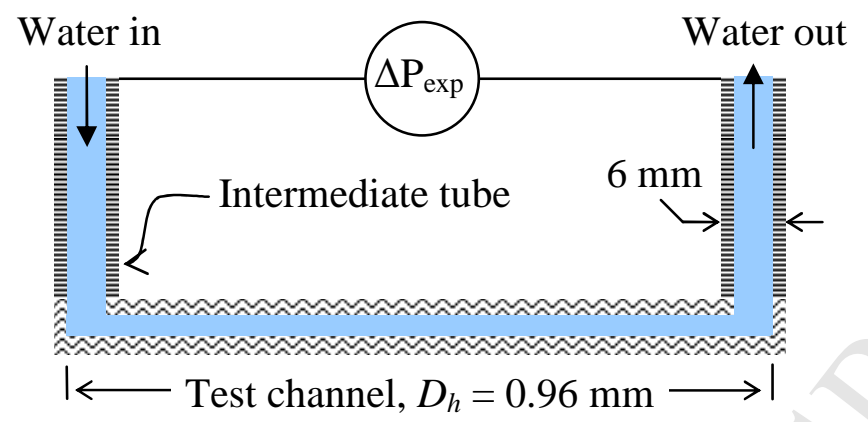

Figure 8. Schematic view of the fluid flow in the test section.

\section{Frictional pressure drop}

The frictional pressure loss is expressed as:

$$
\Delta P_{\text {frict }}=4 f_{p} \frac{G^{2}}{2 \rho_{l}} \frac{L}{D_{h}}
$$

290 wherein $G$ is the mass flux, $\rho_{l}$ is the liquid density, $L$ is the test-channel length, $D_{h}$ is the testchannel hydrodynamic diameter and $f_{p}$ is the single-phase frictional factor, which can be determined by the ratio of the Poiseuille number to the Reynolds number:

$$
f_{p}=\frac{\mathrm{Po}}{\mathrm{Re}}
$$

295 On the operating conditions, the Reynolds number is lower than 1000, and hence, the fluid flow is in laminar regime. For rectangular channels, Shah and London [14] gives an approximation of the Poiseuille number in terms of the geometry ratio as:

$$
\text { Po }=24\left[-0,2537 \zeta^{5}+0,9564 \zeta^{4}-1,7012 \zeta^{3}+1,9467 \zeta^{2}-1,3553 \zeta+1\right]
$$

300 where $\zeta$ is the ratio of the channel height to the channel width. In the present study, $\zeta$ is equal to 0.1 , and therefore Eq. (10) gives Po $=21$.

\section{Singular pressure drop}

The singular pressure loss is expressed as:

$$
\Delta P_{\text {sing }}=\xi \frac{G^{2}}{2 \rho_{l}}
$$

wherein $\xi$ is the singular pressure loss coefficient. This coefficient can be estimated using the case of two $90^{\circ}$ sharp corner elbows with sudden contraction at the inlet and sudden enlargement at the outlet. According to the theory presented in [15], $\xi$ is close to 4.5 . 
From (8), (9) (10) and (12), the experimental pressure drop is expressed as:

$$
\Delta P_{\exp }=4 \frac{\operatorname{Po}}{\operatorname{Re}} \frac{G^{2}}{2 \rho_{l}} \frac{L}{D_{h}}+\xi \frac{G^{2}}{2 \rho_{l}}
$$

Hence, it is expressed as a function of the liquid velocity $U_{l}$ as:

$$
\Delta P_{\text {exp }}=K_{\text {frict }} U_{l}+K_{\text {sing }} U_{l}^{2}
$$

315

wherein $K_{\text {frict }}$ and $K_{\text {sing }}$ are the constants defined as :

$$
\begin{aligned}
& K_{\text {frict }}=2 \mu_{l} \operatorname{Po} \frac{L}{D_{h}^{2}} \\
& K_{\text {sing }}=\frac{1}{2} \xi \rho_{l}
\end{aligned}
$$

320 These constants can be determined experimentally, giving the experimental Poiseuille number and the singular pressure loss coefficient:

$$
\begin{aligned}
& \text { Po }=\frac{K_{\text {frict }}}{2} \frac{D_{h}^{2}}{\mu_{l} L} \\
& \xi=\frac{2 K_{\text {sing }}}{\rho_{l}}
\end{aligned}
$$

325 Water entered the test section at the ambient temperature $\left(20^{\circ} \mathrm{C}\right)$ and at different mass fluxes varying from 95 to $580 \mathrm{~kg} / \mathrm{m}^{2} \mathrm{~s}$. The measured pressure drop is plotted as a function of the liquid velocity as shown in Figure 9a. A second-order polynomial is fitted with the experimental data, giving $K_{\text {frict }}=8546.5$ and $K_{\text {sing }}=2431.7$. This regression has a determination coefficient greater than 0.9999. Therefore, using Eqs. (17) and (18), Po $=22.3$ and $\xi=4.87$. The frictional and singular pressure drops are then determined as shown in Figure $9 \mathrm{~b}$ according to Eq. (9) and (12).

For the frictional pressure drop, the experimental points show a good agreement with the theoretical solutions of Shah and London [14], with a maximum deviation of $6 \%$. For the singular pressure drop, low deviation is also obtained between the experimental and theoretical values of the singular-pressure-drop coefficient as shown in Table 4. Furthermore, the singular pressure drop is significantly lower than the frictional pressure drop in the test channel. The ratio between them is less than $6 \%$ for Reynolds numbers lower than 200 . 

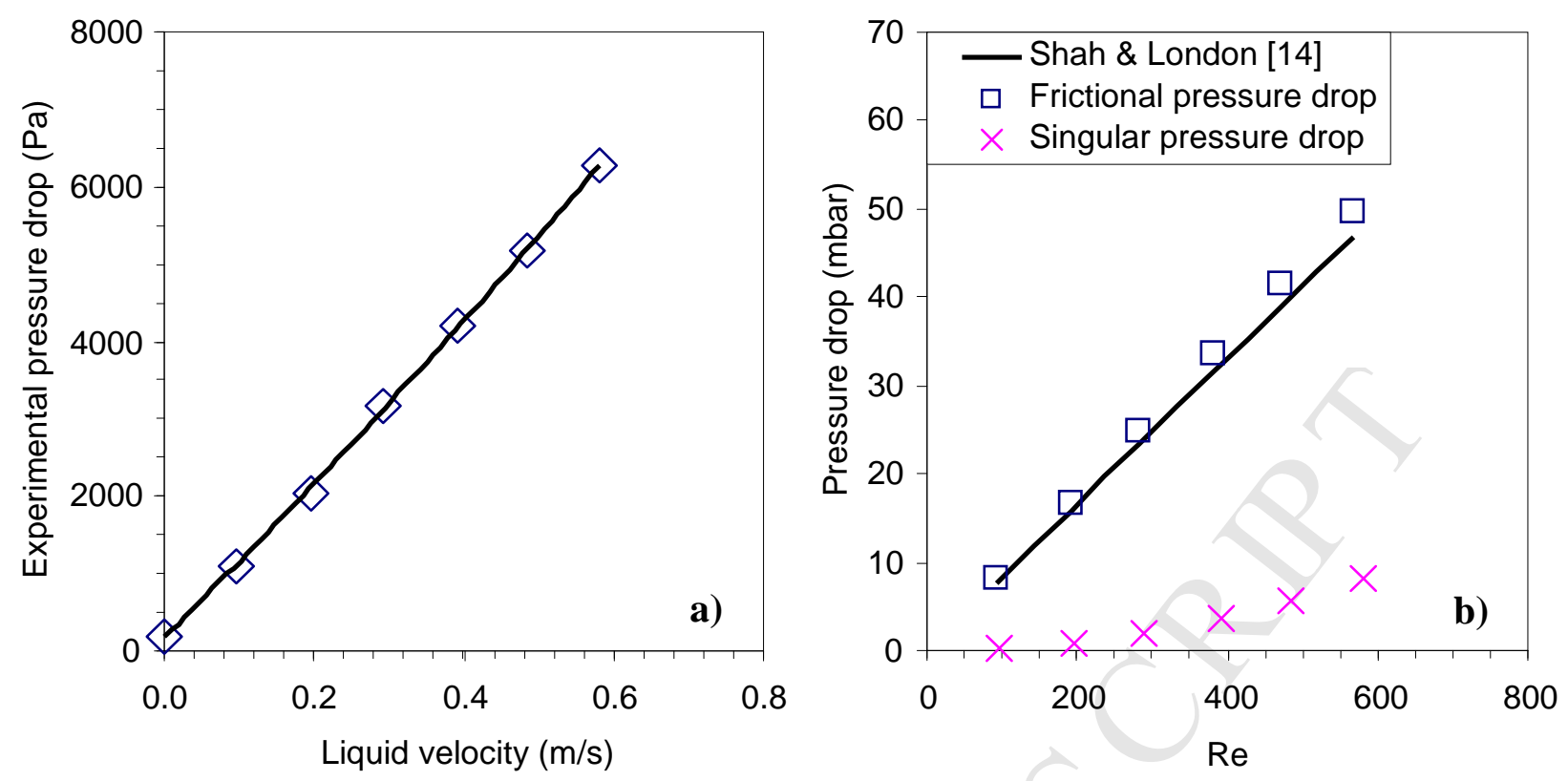

Figure 9. Pressure drops: a) experimental pressure drop and b) frictional and singular pressure drops.

Shown in Figure 10 are the overall single-phase pressure drops measured for all the sample surfaces. The same evolution of the experimental single-phase pressure drops with the Reynolds number is observed, validating the reproducibility of the sample implementation procedure.

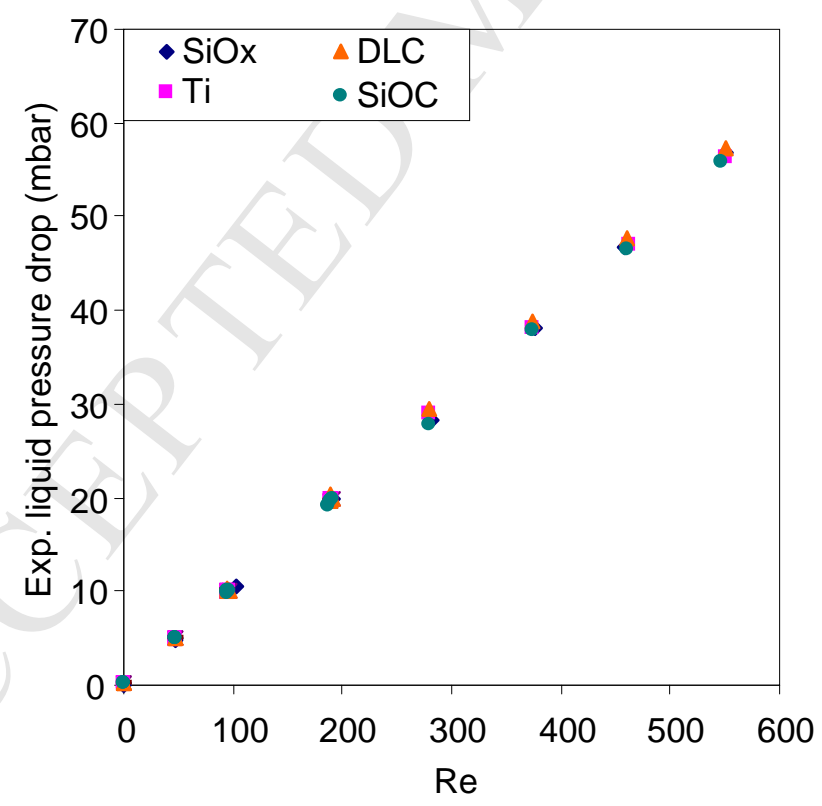

Figure 10. Total liquid pressure drop vs. Reynolds number.

Indeed, the average deviation of the experimental data shown in Figure 10 is about 0.8 mbar, which is in the order of the uncertainty in measurement of the pressure drop. Therefore, the experimental values of Po and $\xi$ given in Table 4 can be used for the all sample surfaces to estimate the single-phase pressure drops. 
Table 4. Single-phase pressure drop constants.

\begin{tabular}{lllll}
\hline Constant & Theoretical value, ref. & Experimental value & Deviation & Deviation (\%) \\
\hline Po & $21,[14]$ & 22.3 & 1.3 & 6 \\
$\xi$ & $4.5,[15]$ & 4.9 & 0.4 & 8 \\
\hline
\end{tabular}

\section{Experimental results}

\subsection{Contact angle}

The contact angles of water on the sample surfaces were measured using the sessile drop technique with KRÜSS EasyDrop systems in a cleanroom at the ambient temperature (cf. 2.2.3). Pictures of water drops on different sample surfaces are shown in Figure 11.

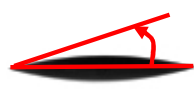

$26^{\circ}$

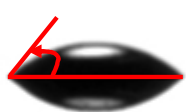

$49^{\circ}$

SiOx surface

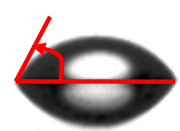

$63^{\circ}$

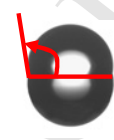

$104^{\circ}$

DLC surface SiOC surface

Figure 11. Static contact angles of a water-droplet on the sample surfaces at room temperature.

The SiOx surface shows a relatively high wettability; whereas the SiOC surface is an unwetted (hydrophobic) surface. The Ti and DLC surfaces are both wetted (hydrophilic) and have static contact angles $(\theta)$ of $49^{\circ}$ and $63^{\circ}$, respectively. The contact angle hysteresis $\Delta \theta$ of each sample surface is also determined by measurements of receding and advancing contact angles $\left(\theta_{a}\right.$ and $\theta_{r}$, respectively). The results of contact angle measurements are summarized in Table 5.

Table 5. Contact angle measurements.

\begin{tabular}{lllll}
\hline Surface & $\theta\left({ }^{\circ}\right)$ & $\theta_{a}\left({ }^{\circ}\right)$ & $\theta_{r}\left(^{\circ}\right)$ & $\Delta \theta\left(^{\circ}\right)$ \\
\hline SiOx & 26 & 38 & 15 & 23 \\
Ti & 49 & 82 & 36 & 46 \\
DLC & 63 & 94 & 51 & 43 \\
SiOC & 104 & 108 & 96 & 12 \\
\hline
\end{tabular}

\subsection{Two-phase pressure drop}

As shown in Section 4.3, the surface wettability has a negligible impact on the single-phase pressure drop. However, in boiling conditions, the surface wettability can play a significant role because of surface tension force generated at the fluid-wall interface. This remark is highlighted by experimental measurements as shown in Figure 12. For various samples with various contact angles, different evolution curves of two-phase pressure drop as functions of vapour quality are obtained.

Indeed, at the operating mass fluxes, it is noticed that the two-phase pressure drop decreases with the contact angle. Especially, between SiOx highly-wetted surface and SiOC unwetted surface, the average deviation is about $170 \%$. The impact of contact angle on two-phase pressure drop can be related to its impact on the surface tension force generated at the triple contact line. For wetted surfaces, this force acts to reduce the dry zone perimeter, and a decrease of the contact angle leads to an increase of this effect. However, for unwetted 
surface, as shown by Phan et al. [17], the surface tension force tends to maintain the bubbles at the solid wall, increasing the frictional pressure drop of the moving fluid.

For all the samples, the two-phase pressure drop increases when the mass flux or the vapour quality increases. The dependence of the two-phase pressure drop on the vapour quality can 400 be fitted by linear or second-order regression with a regression coefficient greater than 0.999 .
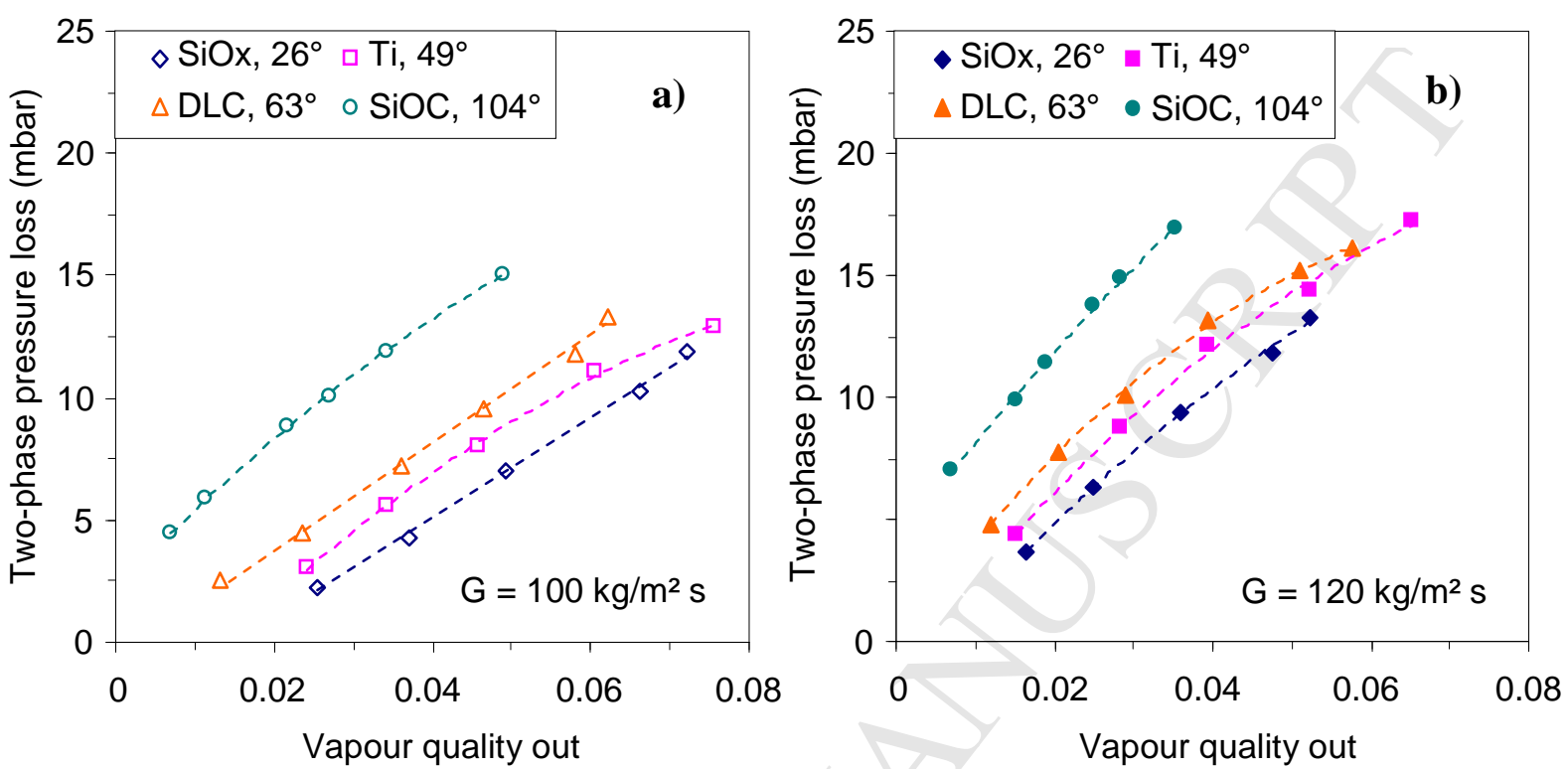

Figure 12. Two-phase pressure drops: a) at $100 \mathrm{~kg} / \mathrm{m}^{2} \mathrm{~s}$ and b) at $120 \mathrm{~kg} / \mathrm{m}^{2} \mathrm{~s}$.

\section{Proposed two-phase pressure drop model}

The two-phase pressure drop is classically calculated as a sum of the static pressure drop $\Delta P_{\text {static }}$, the momentum pressure drop $\Delta P_{a c}$ and the frictional pressure drop $\Delta P_{\text {frict }}$ as:

$$
\Delta P_{t p}=\Delta P_{\text {static }}+\Delta P_{a c}+\Delta P_{\text {frict }}
$$

410 Eq. (19) implies the following equation of pressure gradient per unit length:

$$
\frac{d P_{t p}}{d z}=\frac{d P_{\text {static }}}{d z}+\frac{d P_{a c}}{d z}+\frac{d P_{\text {frict }}}{d z}
$$

In the present study, because the test channel is in horizontal position, the static pressure drop can be neglected, leading to:

$\frac{d P_{t p}}{d z}=\frac{d P_{a c}}{d z}+\frac{d P_{f r i c t}}{d z}$

wherein, the gradients per unit length of the momentum and frictional pressure drops can be estimated using the homogeneous or separated flow models for flow inside plain tubes such as: Lockhart and Martinelli [19], Mishima and Hibiki [20], Friedel [21], Chisholm [22], 
Bankoff [23], and Muller-Steinhagen and Heck [24]. A complete review of these models can be found in the book of Thome [25].

In the homogeneous model, the two-phase flow is approached by a homogeneous fluid which has a homogeneous viscosity $\mu_{t p}$ and a homogeneous density $\rho_{t p}$ defined as:

425

$$
\begin{aligned}
& \mu_{t p}=x \mu_{g}+(1-x) \mu_{l} \\
& \rho_{t p}=\rho_{l}\left(1-\varepsilon_{h}\right)+\rho_{g} \varepsilon_{h}
\end{aligned}
$$

wherein, $x$ is the vapour quality; $\mu_{l}$ and $\mu_{g}$ are the liquid and gas viscosities, respectively; $\rho_{l}$ and $\rho_{g}$ are the liquid and gas velocities, respectively; and $\varepsilon_{h}$ is the homogenous void fraction 430 determined as:

$$
\varepsilon_{h}=\frac{1}{1+\frac{1-x}{x} \frac{\rho_{g}}{\rho_{l}}}
$$

The separated flow model considers the two phases artificially separated into two streams, each flowing in its own channel. The areas of the two channels are proportional to the void 435 fraction $\varepsilon_{s f}$. Numerous methods are available for predicting the void fraction. In the present study, the correlation of Steiner [26] is used as recommended by Thome [25]:

$$
\varepsilon_{s f}=\frac{x}{\rho_{g}}\left([1+0.12(1-x)]\left(\frac{x}{\rho_{g}}+\frac{1-x}{\rho_{l}}\right)+\frac{1.18(1-x)\left[g \sigma\left(\rho_{l}-\rho_{g}\right)\right]^{0.25}}{G^{2} \rho_{l}^{0.5}}\right)^{-1}
$$

wherein, $g$ is the gravity, $\sigma$ is the liquid-vapour surface tension and $G$ is the mass flux.

The present experimental data are then compared to the data given by the above correlations, as shown in Figure 13 and Figure 14. It is important to notice that for the correlation of Lockhart and Martinelli [19], the case of laminar liquid flow and turbulent gas flow is applied for the present study, since the liquid Reynolds number is about 400 and the vapour Reynolds number is about 8000 .

It is shown that the method of Lockhart and Martinelli [19] gives the best estimation for the experimental-data evolution trend and values, especially for wetted surfaces. The second best method is the correlation of Bankoff [23] and the third best is the correlation of MullerSteinhagen and Heck [24]. However, none of these correlations predicts the dependence of the two-phase pressure drop with the contact angle. 


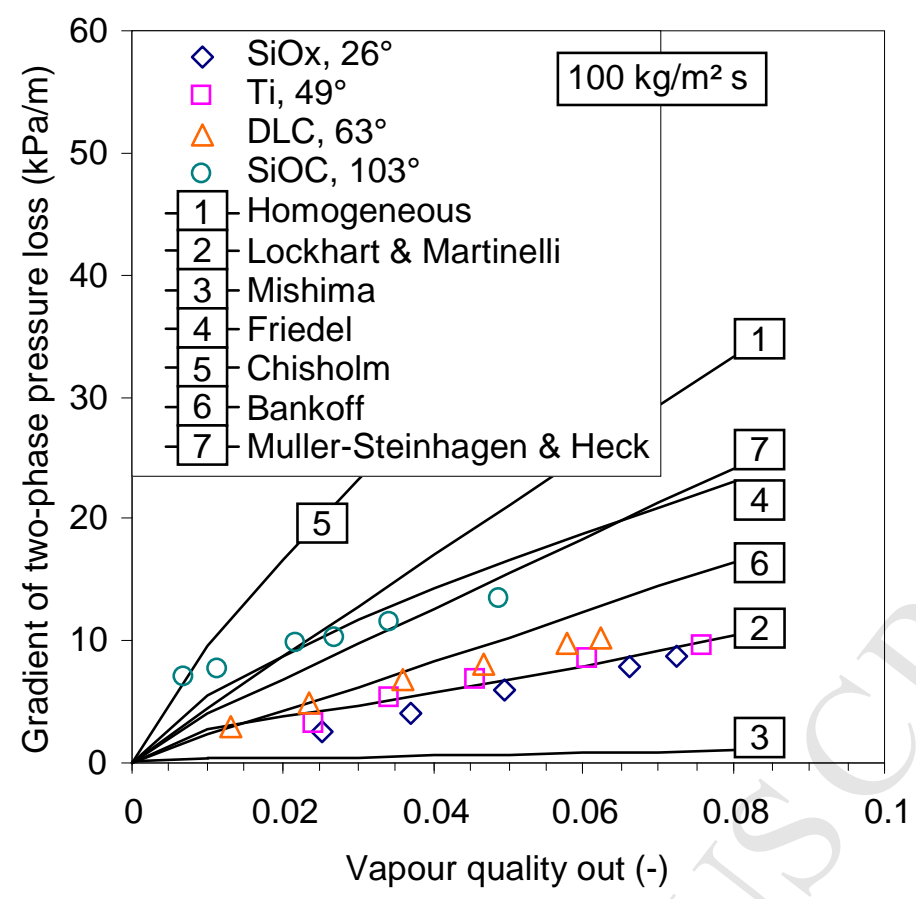

Figure 13. Comparison between exp. and theoretical data of two-phase pressure drop gradient at $100 \mathrm{~kg} / \mathrm{m}^{2} \mathrm{~s}$.

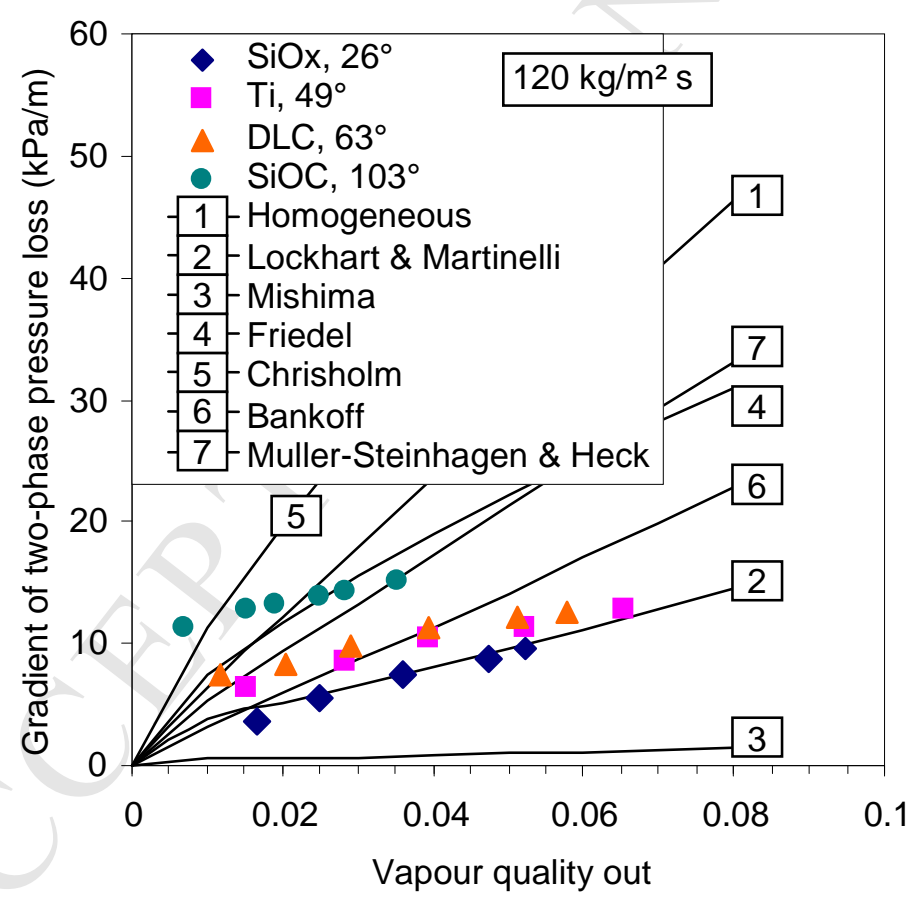

Figure 14. Comparison between exp. and theoretical data of two-phase pressure drop gradient at $120 \mathrm{~kg} / \mathrm{m}^{2} \mathrm{~s}$.

460 For a better prediction, it is necessary to take into account the pressure drop caused by the surface tension force generated at the triple contact line. This pressure drop is called "wetting pressure drop" $P_{\theta}$. It is also called "triple-line pressure drop" by Yu et al. [6]. Therefore, Eq. (21) is modified as:

$\frac{d P_{t p}}{d z}=\frac{d P_{a c}}{d z}+\frac{d P_{f r i c t}}{d z}+\frac{d P_{\theta}}{d z}$ 
Thus, the gradient of the wetting pressure drop can determined as:

$$
\frac{d P_{\theta}}{d z}=\frac{d P_{t p}}{d z}-\left(\frac{d P_{a c}}{d z}+\frac{d P_{\text {frict }}}{d z}\right)
$$

wherein, the two-phase pressure drop gradient is determined by experimental measurements, 470 and the gradients of the momentum and frictional pressure drops can be estimated by the correlation of Lockhart and Martinelli [19] which give the best estimation:

$$
\frac{d P_{\theta}}{d z}=\left(\frac{d P_{t p}}{d z}\right)_{\exp }-\left(\frac{d P_{a c}}{d z}+\frac{d P_{f r i c t}}{d z}\right)_{\text {Lockhart and Martinelli }}
$$

At a first approximation, the wetting pressure drop is assumed to be independent of the vapour quality and mass flux. Hence, for a given contact angle, the wetting pressure drop is taken as the statistical average value as:

$$
\frac{d P_{\theta}}{d z}=\frac{1}{N} \sum_{i=1}^{N}\left[\left(\frac{d P_{t p}}{d z}\right)_{\exp }^{i}-\left(\frac{d P_{a c}}{d z}+\frac{d P_{\text {frict }}}{d z}\right)_{\text {Lockhart and Martinelli }}^{i}\right]
$$

wherein, $N$ is the number of experimental points for each contact angle.

Besides, the wetting pressure drop gradient can be analytically determined by a simple model in which, a confined bubbly (or slug) with a length $L_{b}$ circulates inside a circular tube of hydraulic diameter $D_{h}$ as shown in Figure 15.

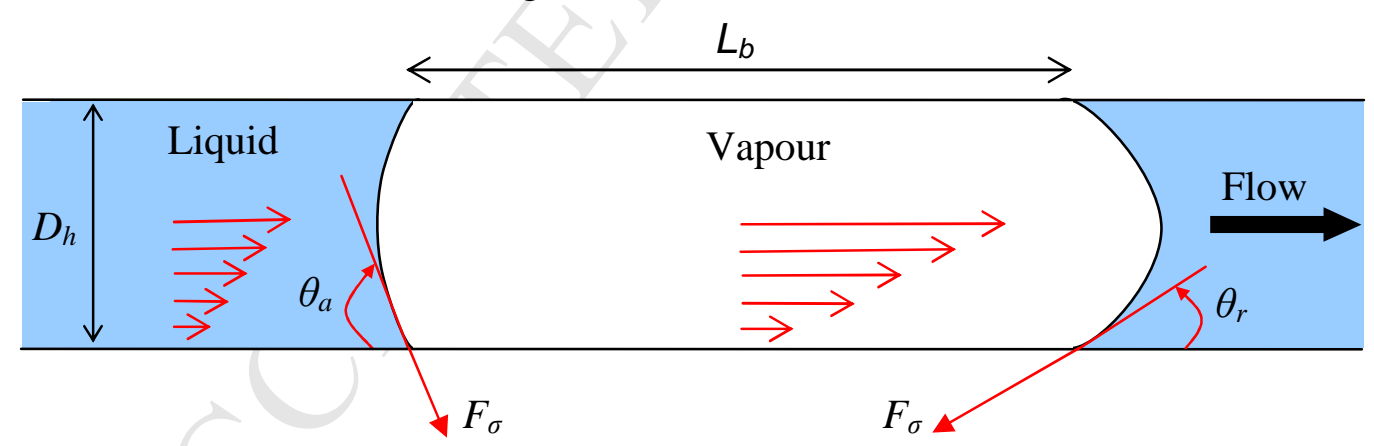

485

Figure 15. Schematically view of a confined bubble or slug inside a circular tube.

At bubble head and tail, the contact angles are the advancing contact angle $\theta_{a}$ and the receding contact angle $\theta_{r}$, respectively. For wetted surfaces, the surface tension force at the bubble tail acts to push the bubble in the flow direction, but this force at the bubble head acts to pull the bubble backward. The wetting pressure drop is thereby defined as the pressure difference generated by the difference of the surface tension forces at the bubble head and tail. Thus, it can be determined as:

$$
\Delta P_{\theta}=\frac{4 \sigma\left(\cos \theta_{r}-\cos \theta_{a}\right)}{D_{h}}
$$


The gradient per unit length of the wetting pressure drop can be thereby expressed as:

$$
\frac{d P_{\theta}}{d z}=\frac{4 \sigma\left(\cos \theta_{r}-\cos \theta_{a}\right)}{D_{h}} \frac{1}{L_{b}}
$$

In boiling conditions, the advancing and receding contact angles of a bubble are difficult to be measured. Furthermore, because of the high ratio of the vapour velocity to the liquid velocity, the liquid-vapour interfaces are significantly pushed by the vapour, leading to decrease the advancing and receding contact angles. At a first approximation, the advancing contact angle $\theta_{a}$ is assumed to decrease to the value of the static contact angle $\theta$ and the receding contact angle $\theta_{r}$ is assumed to decrease to be equal to 0 . This hypothesis implies:

505

$$
\frac{d P_{\theta}}{d z}=K_{\theta}(1-\cos \theta)
$$

wherein $K_{\theta}$ is a constant defined as:

$$
K_{\theta}=\frac{4 \sigma}{D_{h}} \frac{1}{L_{b}}
$$

510 Eq. (33) shows that the gradient of the wetting pressure drop has a linear relation with (1$\cos \theta$ ). In order to validate this observation, the gradient of the wetting pressure drop determined by Eq. (29) is plotted as a function of $(1-\cos \theta)$, as shown in Figure 16.

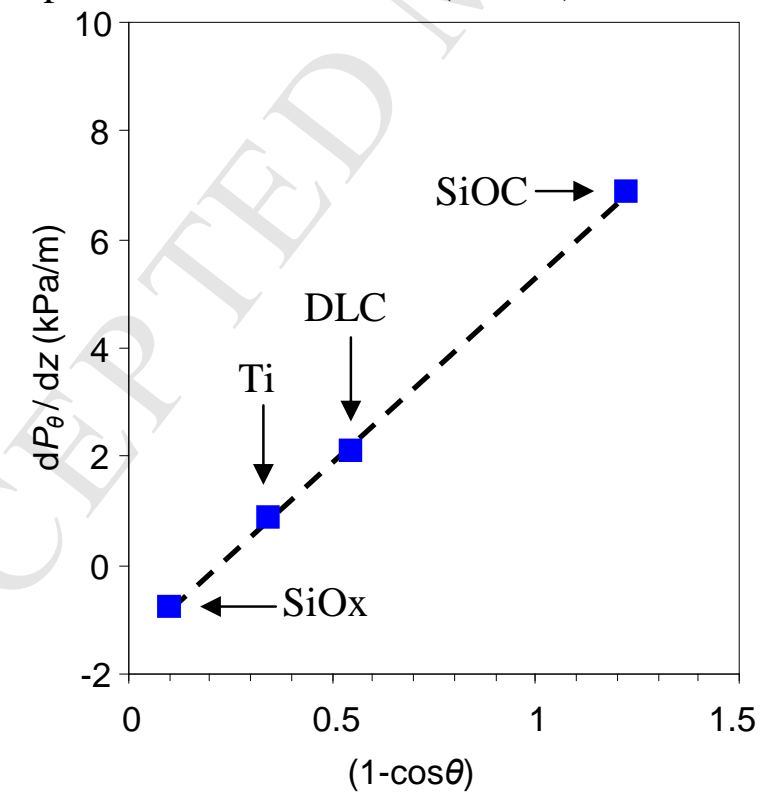

Figure 16. Gradient of the wetting pressure drop vs. $(1-\cos \theta)$.

Indeed, it is observed that the data evolution can be fitted by a linear regression with a regression coefficient greater than 0.999, for different surface coatings: SiOx, DLC and SiOC. The reference is still the Ti surface. The following correlation is thereby suggested to estimate the wetting pressure drop: 
$\frac{d P_{\theta}}{d z}=10^{3} \times[6.81(1-\cos \theta)-1.51]$

Therefore, using Eq. (26) where the gradients of the momentum and friction pressure drops are estimated by the correlation of Lockhart and Martinelli [19], and the gradient of the wetting pressure is determined by Eq. (34), the two-phase pressure can be approximated.

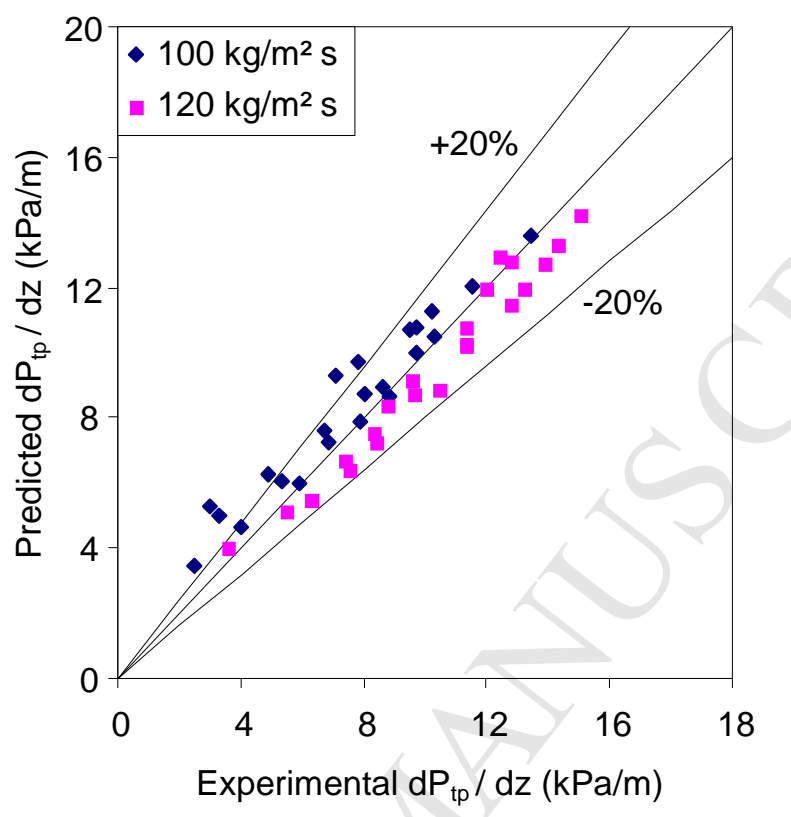

Figure 17. Comparison of the predicted and experimental values of the wetting pressure-drop gradient.

Figure 17 shows a good agreement of the predicted and measured two-phase pressure drop. Indeed, about $86 \%$ of the data are included within the lines of $20 \%$ error.

The development of such surfaces has many potential applications in hydraulic and thermal management of systems. In micro heat sinks, the pressure drops are usually sensitive to high pressure drops. The reduction of the hydraulic diameter leads indeed to a higher heat transfer coefficient but also higher pressure drops. In configuration with many parallel channels, the pressure drops can induce high two-phase flow instabilities [18]. Applications in thermal management of microelectronics, power systems, air conditioning where micro-channels heat exchangers are now common devices could be targeted.

\section{Conclusion}

In the present study, the two-phase pressure drop of water flow boiling in a horizontal microchannel was investigated for various sample surfaces having different contact angles of $26^{\circ}, 49^{\circ}, 63^{\circ}$ and $104^{\circ}$. It was observed that the total two-phase pressure drop significantly

545 increases with the static contact angle. In particular, the average deviation between the highlywetted and the unwetted surfaces is about $170 \%$.

The experimental data were compared to the data given by some well-known models [19][26]. It was shown that the method of Lockhart and Martinelli [19] gives the best estimation

550 for the experimental-data evolution trend and values, especially for the wetted sample surfaces (SiOx, Ti and DLC). The second best method is the correlation of Bankoff [23] and the third best is the correlation of Muller-Steinhagen and Heck [24]. 
However, none of these correlations predicts the dependence of the two-phase pressure drop with the contact angle $\theta$. Therefore, we suggested taking into account the "wetting pressure drop", caused by the surface tension forces generated at the triple contact lines. The wetting pressure drop is calculated as a difference between the experimental two-phase pressure drop and the frictional and momentum pressure drops given by the model of Lockhart and Martinelli [19]. It was shown that the wetting pressure drop is proportional to $(1-\cos \theta)$. A correlation is thereby suggested to predict the wetting pressure as a function of the static contact angle. The developed model is in good agreement with the experimental data with $86 \%$ of the data included within the lines of $20 \%$ error.

\section{Appendix: Data reduction for boiling tests}

\section{$\underline{\text { Heat fluxes }}$}

565 As shown in Section 4, heat losses by electrical generation are negligible. Therefore, the local heat flux exchanged between the fluid and the wall at section $i$ of the sample surface is calculated as:

$$
q_{i}=\frac{I V_{i}}{A_{h, i}}
$$

570 wherein $I$ is the current and $V_{i}$ and $A_{h, i}$ are the voltage and the area of section $i$, respectively.

The average heat flux along the test channel is calculated as:

$$
\bar{q}=\frac{I V}{A_{h}}
$$

575 wherein $V$ is the overall voltage and $A_{h}$ is the overall heat exchange area between the working fluid and the sample surface.

However, as mentioned in Section 4.1, due to air convection and radiation around the test section, the working fluid looses a part of its energy $Q^{\circ}$ loss when flowing along the test channel even though no electrical power is generated:

$Q_{\text {loss }}^{o}=\dot{m} C_{p}\left[T_{f, \text { in }}-T_{f, \text { out }}^{o}\right]$

wherein $\dot{m}$ is the mass flow, $C_{p}$ is the liquid specific heat, $T_{f, i n}$ is the fluid inlet temperature and $T_{f, \text { out }}^{o}$ is the fluid outlet temperature when the fluid is not heated by electrical power from 585 the sample surface.

The average heat loss flux before generation of electrical power is approximated as:

$$
\bar{q}_{\text {loss }}^{o}=\frac{Q_{\text {loss }}^{o}}{A_{h}}
$$


Two-phase length

An iterative method is used to calculate the single-phase length $z_{\text {onb }}$ where bulk boiling starts, i.e. where the fluid bulk temperature is equal to the saturation temperature at the local pressure.

595 Initial condition for the iteration is:

$z_{\text {onb }}=L$

wherein $L$ is the test-channel length.

600 At each iteration step, the absolute pressure $P_{\text {onb }}$ and saturation temperature $T_{s, \text { onb }}$ are calculated, updating the value of the single-phase length.

$$
P_{\text {onb }}=P_{\text {in }}-4 \frac{\text { Po }}{\operatorname{Re}} \frac{G^{2}}{2 \rho_{l}} \frac{z_{\text {onb }}}{D_{h}}
$$

wherein $P_{\text {in }}$ is the absolute pressure at the inlet of the test section and Po is the Poiseuille number determined by single-phase tests (cf. Section 4). The singular pressure drop at the inlet of the test channel is not taken into account in Eq. (40) since it is less than $2 \%$ of the overall single-phase pressure drop as shown in Section 4.

The saturation temperature is determined using a second-order polynomial regression given by REFPROP 7.0, developed by NIST (2002):

$$
T_{s, \text { onb }}=-1.17405 \times 10^{-5} P_{\text {onb }}^{2}+5.14761 \times 10^{-2} P_{\text {onb }}+59.8705
$$

wherein $P_{\text {onb }}$ is in mbar and $T_{s, \text { onb }}$ is in ${ }^{\circ} \mathrm{C}$.

615 The energy balance from the inlet of the test channel to the position where bulk boiling starts implies:

$$
\dot{m} C_{p}\left(T_{s, o n b}-T_{f, \text { in }}\right)=\left(\bar{q}-\bar{q}_{\text {loss }}^{o}\right) W z_{\text {onb }}
$$

wherein $W$ is the test channel width.

620

Therefore, the following expression of the single-phase length is obtained:

$$
z_{\text {onb }}=\frac{\dot{m} C_{p}\left(T_{s, b o i l}-T_{f, i n}\right)}{\left(\bar{q}-\bar{q}_{\text {loss }}^{o}\right) W}
$$

The iteration stops when the convergence criterion is obtained:

$\left|z_{\text {onb }}^{n+1}-z_{\text {onb }}^{n}\right| \leq 10^{-6}$

wherein $n$ is the number of iteration. 
630

Hence, the two-phase length $L_{t p}$ is determined as:

$$
L_{t p}=L-z_{o n b}
$$

\section{Two-phase pressure drop}

The overall two-phase pressure drop $\Delta P_{t p}$ along the test channel is calculated as:

$$
\Delta P_{t p}=\Delta P_{\exp }-\left(P_{\text {in }}-P_{\text {onb }}\right)
$$

635

640

wherein $\Delta P_{\text {exp }}$ is the pressure drop measured experimentally and $\left(P_{i n}-P_{\text {onb }}\right)$ is the singlephase pressure drop. The singular pressure drop at the outlet of the test channel is not taken into account in the above equation since it is less than $3 \%$ of the overall single-phase pressure drop as shown in Section 4.

Thus, the average gradient per unit length of the two-phase pressure drop is calculated as:

$$
\left(\frac{d P}{d z}\right)_{t p}=\frac{\Delta p_{t p}}{L_{t p}}
$$

\section{$\underline{\text { Vapour quality }}$}

The variation of the vapour quality is calculated using energy balance as:

$$
\Delta x_{i}=\frac{A_{h, i}\left(q_{i}-\bar{q}_{\text {loss }}^{o}\right)-\dot{m} C_{p, i}\left(T_{s, i}-T_{f, i}\right)}{\dot{m} H_{l v, i}}
$$

wherein $H_{l v, i}$ is the latent heat of vaporisation at section $i$.

The vapour quality is equal to zero when bulk boiling starts. It is negative on subcooled conditions and positive on boiling conditions.

\section{Operating conditions}

A Matlab program was written in order to determine the parameters of interest according to the above equations. Thermodynamic properties of water are calculated with the computer code REFPROP 7.0, developed by NIST (2002). Experimental parameters and operating conditions are summarized in Table 6 . The measurement uncertainties are estimated using the error propagation law suggested by Kline and McClintock [16]

Table 6. Operating parameters and uncertainties.

\begin{tabular}{lll}
\hline Parameter & Range & Uncertainty \\
\hline$D_{h}(\mathrm{~mm})$ & 0.96 & $\pm 2 \%$ \\
$G\left(\mathrm{~kg} / \mathrm{m}^{2} \mathrm{~s}\right)$ & $80-120$ & $\pm 2 \%$ \\
$P_{\text {in }}(\mathrm{mbar})$ & 1000 & $\pm 0.2 \%$ \\
$P_{\text {in }}-P_{\text {out }}(\mathrm{mbar})$ & $0-100$ & $\pm 0.3 \%$ \\
$\bar{q}\left(\mathrm{~kW} / \mathrm{m}^{2}\right)$ & $30-100$ & $\pm 2 \%$ \\
$x$ & $-0.1-0.1$ & $\pm 2 \%$ \\
\hline
\end{tabular}




\section{References}

[1] P. Kew, K. Cornwell, Correlations for the prediction of boiling heat transfer in smalldiameter channels, Appl. Thermal Eng., 17 (1997), 705-715.

[2] S.G. Kandlikar, W.J. Grande, Evolution of microchannel flow passages-Thermohydraulic performance and fabrication technology, Heat Transfer Engineering 25 (2003), 3-17.

[3] P. Rapolu, S.Y. Son, Capillary effects on two-phase flow resistance in microchannels, Proceedings of $18^{\text {th }}$ Int. Symposium on Transport Phenomena (2007), 1431-1436.

665 [4] C.Y. Lee, S.Y. Lee, Pressure drop of two-phase plug flow in round mini-channels: Influence of surface wettability, Exp. Thermal and Fluid Science 32 (2008), 1716-1722.

[5] C.Y. Lee, S.Y. Lee, Pressure drop of two-phase dry-plug flow in round mini-channels: Effect of moving contact line, Exp. Thermal and Fluid Science 34 (2010), 1-9.

[6] D. Yu, C. Choi, M.-H. Kim, The pressure drop and dynamic contact angle of motion of triple-lines in hydrophobic microchannels, Proceedings of $8^{\text {th }}$ Int. Conf. on Nanochannels, Microchannels and Minichannels (2010), August 1-5, Montreal, Canada.

[7] T.Y. Liu, P.L.Li, C.W. Liu, C. Gau, Boiling flow characteristics in microchannels with very hydrophobic surface to super-hydrophilic surface, International Journal of Heat and Mass Transfer 54 (2011) 126-134.

675 [8] C. Choi, J.S. Shin, D. I.Y. Kim, M.H. Kim, Flow boiling behaviors in hydrophilic and hydrophobic microchannels, Experimental Thermal and Fluid Science, In Press, Corrected Proof, doi:10.1016/j.expthermflusci.2010.07.003.

[9] A. Billard, F. Perry, Pulvérisation cathodique magnétron, Techniques de l'Ingénieur M1654 (2005), 1-17.

680 [10] C. Chouquet, Élaboration et caractérisation de revêtements type «Diamond-Like Carbon » déposés par un procédé chimique en phase vapeur assisté par un plasma basse fréquence, PhD thesis, Institut National Polytechnique de Lorraine (2008), Lorraine, France.

[11] N. Blondiaux, E. Scolan, A.M. Popa, J. Gavillet, R. Pugin, Fabrication of superhydrophobic surfaces with controlled topography and chemistry, Applied Surface Science 256 (2009), S46-S53.

[12] J. Nestler, A. Morschhauser, K. Hiller, T. Otto, S. Bigot, J. Auerswald, H. F. Knapp, J. Gavillet, T. Gessner, Polymer lab-on-chip systems with integrated electrochemical pumps suitable for large-scale fabrication, Int. J. Adv. Manuf. Technol. 47 (2010), 137$690 \quad 145$.

[13] S. Zanini, C. Riccardia, M. Orlandib, E. Grimoldia, Characterisation of SiOxCyHz thin films deposited by low-temperature PECVD, Vacuum 82 (2008), 290-293.

[14] R. Shah, A. London, Laminar Flow Forced Convection in Ducts, Academic Press, 1978.

[15] A. Lallemand, Écoulements des fluides- Écoulements en conduites. Réseaux, Techniques de l'Ingénieurs BE8161 (2001), 1-19.

[16] S.J. Kline, F.A. McClintock, Describing uncertainties in single-sample experiments, Mech. Eng. 75 (1953), 3-8. 
[17] H. T. Phan, N. Caney, P. Marty, S. Colasson, J. Gavillet, Surface wettability controlled by nanocoating: The effects on pool boiling heat transfer and nucleation mechanism, I. J. Heat and Mass transfer 52 (2009), 5459-5471.

[18] D. Brutin, F. Topin, L. Tadrist, Experimental study of unsteady convective boiling in heated minichannels, Int. J. Heat and Mass Transfer 46 (2003), 2957-2965.

[19] R.W. Lockhart, R.C. Martinelli, Proposed correlation data for isothermal two-phase twocomponent flow in pipes, Chem. Eng. Progr. 45 (1949), 39-45.

[20] K. Mishima, T. Hibiki, Some characteristics of air-water two-phase flows in small diameter vertical tubes, Int. J. Multiphase flow 22 (1996), 703-712.

[21] L. Friedel, Improved friction pressure drop correlations for horizontal and vertical twophase pipe flow, European Two-phase Flow Group Meeting (1979), Ispra, Italy.

[22] D. Chisholm, Pressure gradients due to friction during the flow of evaporating two-phase mixtures in smooth tubes and channels, Int. J. Heat and Mass Transfer 16 (1973), 347358.

[23] S. G. Bankoff, A variable density single-fluid model for two-phase flow with particular reference to steam-water flow, J. Heat Transfer 82 (1960), 265-272.

[24] H. Muller-Steinhagen, K. Heck, A simple pressure drop correlation for two-phase flow in pipes, Chem. Eng. Process. 20 (1986), 297-308.

[25] J.R. Thome, Heat Transfer engineering data book III, Web-based reference book available on web at www.wlv.com/products (2010).

[26] D. Steiner, Heat transfer to boiling saturated liquids, VDI-Warmeatlas (VDI Heat Atlas), Editor: Verein Deutscher Ingenieure, VDI-Gessellschaft Verfahrenstechnik und Chemieingenieurwesen (GCV), Translator: J.W. Fullarton, Dusseldorf, 1993.

\section{Nomenclature}

$A_{h} \quad$ heat exchange area, $\mathrm{m}^{2}$

$C_{p} \quad$ specific heat or liquid specific heat if no subscript is mentioned, $\mathrm{J} / \mathrm{kg} \mathrm{K}$

$D_{h} \quad$ hydrodynamic diameter, $\mathrm{m}$

$f_{p} \quad$ single-phase frictional factor, $\mathrm{Po} / \mathrm{Re},-$

$g \quad$ gravity, $\mathrm{m} / \mathrm{s}^{2}$

$G$ mass flux, $\mathrm{kg} / \mathrm{m}^{2} \mathrm{~s}$

$730 \quad H_{l v}$

evaporation latent heat, $\mathrm{J} / \mathrm{kg}$

I current, A

L length, $\mathrm{m}$

$L_{c} \quad$ capillary length, $\left(\frac{\sigma_{l v}}{g\left(\rho_{l}-\rho_{v}\right)}\right)^{1 / 2}, \mathrm{~m}$

$\dot{m} \quad$ mass flow rate, $\mathrm{kg} / \mathrm{s}$

$735 n$ number, -

$P \quad$ pressure, $\mathrm{Pa}$

$\triangle P \quad$ pressure drop, $\mathrm{Pa}$

$q \quad$ heat flux, $\mathrm{W} / \mathrm{m}^{2}$

$\bar{q} \quad$ average heat flux, $\mathrm{W} / \mathrm{m}^{2}$

$740 \quad \bar{q}_{\text {loss }}^{o}$ average heat loss flux before generation of electrical power, $\mathrm{W} / \mathrm{m}^{2}$ 
$Q_{d, \text { loss }} \quad$ electrical power loss by conduction through a Pyrex wafer, W

$Q_{e, f} \quad$ electrical power towards a fluid, W

$Q_{e} \quad$ electrical power, W

745

$Q_{\text {loss }}^{o} \quad$ heat loss before generation of electrical power due to air convection and radiation, $\mathrm{W}$

$Q_{\text {loss }} \quad$ overall heat loss due to electrical power generation, $Q_{\text {loss }}=Q_{d, \text { loss }}+Q_{u, \text { loss }}, \mathrm{W}$

$Q_{u, l o s s} \quad$ part of $Q_{e, f}$ dissipated to the ambient, W

$T \quad$ temperature, $\mathrm{K}$

$T^{\circ} \quad$ temperature before generation of electrical power, $\mathrm{K}$

$750 U \quad$ velocity, $\mathrm{m} / \mathrm{s}$

$V \quad$ tension, $\mathrm{V}$

W width, $\mathrm{m}$

$x \quad$ vapour quality, -

$\Delta x \quad$ variation of vapour quality, -

$z$ coordinate, $\mathrm{m}$

$\varepsilon_{h} \quad$ void fraction given by a homogeneous model, -

$\varepsilon_{s f} \quad$ void fraction given by a separated-flow model, -

\section{Greek symbols}

ratio of the channel height to the channel width, -

contact angle, ${ }^{\circ}$ or rad

$\Delta \theta \quad$ contact angle hysteresis, ${ }^{\circ}$ or rad

$\mu \quad$ dynamic viscosity, Pa.s

$\rho \quad$ density, $\mathrm{kg} / \mathrm{m}^{3}$

\section{Subscripts}

a

ac

$770 \quad b$

$\exp$

$\mathrm{f}$

frict

775

g

in

1

loss

lv

780 onb

out

r

$\mathrm{s}$

static

785 sing

tp

V advancing

acceleration

bubble or slug

experimental

fluid

frictional

gas

portion of the sample surface

at the inlet

liquid

lost

liquid-vapour

onset of nucleate boiling

at the outlet

receding

saturation

static

singular

two-phase

vapour 
$\theta \quad$ wetting

790 Dimensionless numbers

Co confinement number, $L_{c} / D_{h}$

Re Reynolds number, $G D_{h} / \mu_{l}$

Po Poiseuille number, $f_{p} \operatorname{Re}$

795 Mathematical functions

$$
\begin{array}{ll}
K_{\text {frict }} & K_{\text {frict }}=2 \mu_{l} \mathrm{Po} \frac{L}{D_{h}^{2}} \\
K_{\text {sing }} & K_{\text {sing }}=\frac{1}{2} \xi \rho_{l}
\end{array}
$$

